\title{
ESTRATIGRAFIA E EVOLUÇÃO DE UM ESPORÃO ARENOSO EM AMBIENTE MACROMARÉ: PONTA DA AREIA - SÃO LUÍS - MARANHÃO - BRASIL
}

\author{
SAND SPIT STRATIGRAPHY AND EVOLUTION IN MACROTIDAL ENVIRONMENT: PONTA \\ DA AREIA - SAO LUIS - MARANHAO - BRAZIL
}

\section{Leonardo Gonçalves de LIMA ${ }^{1}$, Saulo Santiago de ALBUQUERQUE ${ }^{2}$, Gabriel Silva CERVEIRA $^{2}$, Cláudia Klose Parise ${ }^{2}$, Matheus Seguins FERREIRA ${ }^{3}$, Brunno Jansen FRANCO $^{3}$}

${ }^{1}$ Departamento de Oceanografia e Limnologia, Universidade Federal do Maranhão-UFMA. Av. dos Portugueses, 1966 - Vila Bacanga, São Luís - MA. E-mails: paleonardo_7@hotmail.com; claudiakparise@gmail.com;

${ }^{2}$ Programa de Pós-Graduação em Oceanografia. Universidade Federal do Maranhão-UFMA. E-maisl: saulo_santiago@hotmail.com; sator93@hotmail.com;

${ }^{3}$ Graduação em Oceanografia. Universidade Federal do Maranhão-UFMA.

E-mails: matheus.seguins@hotmail.com; brunno_jfranco@hotmail.com

\author{
Introdução \\ Material e Métodos \\ Resultados \\ Discussão \\ Conclusões \\ Agradecimentos \\ Referências
}

\begin{abstract}
RESUMO - Na Ilha do Maranhão os sistemas de barreiras costeiras podem ser divididos em dois morfotipos principais: (i) Barreiras de Praias Anexadas, que se caracterizam por uma praia anexada transversalmente a topografia antecedente exibindo um gradiente íngreme onde há perda contínua de areia na costa erodida; e (ii) Barreiras de Esporões Arenosos ligadas a Cabeços de Promontórios, que se caracterizam por um sistema laguna-barreira-esporão ancorado longitudinalmente à topografia antecedente. Este último morfotipo origina-se de um amplo transporte de sedimentos via deriva litorânea, cujo prolongamento é geralmente interrompido pelo efeito espigão hidráulico, junto a elevados prismas de maré nas desembocaduras fluviais. O presente estudo utiliza-se de sondagens do tipo percussão e vibrocore para recuperação do registro sedimentar, o qual é descrito quanto a sua compactação, textura, estruturas e fácies sedimentares. Os resultados obtidos demonstram a natureza estratigráfica da barreira costeira na Praia da Ponta da Areia como uma sequência retrogradacional caracterizada pela migração em direção ao continente de um esporão arenoso. A datação radiométrica de sedimentos lagunares aflorantes na praia atestou a idade de 7.240 \pm 30 anos AP indicando que neste tempo, este sistema lagunabarreira-esporão estendia-se mar adentro. Recentemente a construção de um espigão costeiro alterou esta natureza estratigráfica, passando a comportar um sistema progradacional nas imediações do espigão, onde ambientes distais (antepraia) são sotopostos por ambientes proximais (foreshore).
\end{abstract}

Palavras-chave: Barreiras Costeiras. Esporão Arenoso. Praia da Ponta da Areia. Vibrocores. Topografia Antecedente.

ABSTRACT - In the Island of Maranhão, coastal barrier systems can be divided into two main morphotypes: (i) Headland Spit Barriers, which are characterized by a beach attached transversely to the previous topography showing a steep gradient where there is continuous loss of sand on the eroded coast; and (ii) Mailand Beach Barriers, which are characterized by a lagoon-barrier-spur system anchored longitudinally to the previous topography. This latter morphotype originates from a large sediment transport via the coastal drift, whose extension is usually interrupted by the hydraulic spike effect, together with high tide prisms in the river mouths. The present study uses percussion and vibrocore drills to recover the sedimentary record, which is described in terms of its sedimentation, texture, structure and sedimentation facies. The results obtained demonstrate the stratigraphic nature of the coastal barrier in the Ponta da Areia Beach as a retrogradation sequence characterized by the migration towards the continent of a sandy spur. The radiometric dating of lagoon sediments on the beach attested the age of 7,240 \pm 30 years AP indicating that at this time, this lagoon-barrier-spur system extended out to sea. Recently, the construction of a coastal spire has changed this stratigraphic nature, and it has a progradational system in the immediate vicinity of the spike, where distal environments (backshore) are sotopostos by proximal environments (foreshore).

Keywords: Coastal Barrier. Sand Spit. Ponta da Areia Beach. Vibrocores. Ancient Topography.

\section{INTRODUÇÃO}

Estudos envolvendo a geomorfologia de barreiras costeiras são por vezes insuficientes em contemplar a ampla gama de processos atuantes na zona costeira, embora sejam imprescindíveis na avaliação das mudanças tridimensionais em sua morfologia por meio da regra de Bruun (Kraft et al., 1987). A visão estratigráfica nestes estudos, por sua vez, garante um carácter integrador dos sistemas deposicionais, uma vez que não só permite a combinação de estruturas litológicas, físicas e biológicas como também contempla as relações verticais e laterais entre as unidades sedimentares em escalas de tempo mais longo (Walker, 1992). A evolução dos paleoam- 
bientes é inferida a partir da definição de fácies, cujo fundamento principal baseia-se na Lei Walther (Walther, 1894) a qual combina as relações horizontais com o empi-lhamento estratigráfico. Essa noção facilita a compreensão das fácies, pois torna possível sua comparação com ambientes atuais.

Atualmente, cerca de 15\% das costas mundiais são constituídas por barreiras costeiras (Glaeser, 1978), formadas por processos que envolvem a variação do nível do mar, ação de ondas, amplitude de maré, declividade da plataforma continental, aporte de sedimentos, geometria da linha de costa e geologia antecedente (Belknap \& Kraft, 1985). As planícies costeiras e a plataforma continental são geralmente locais de importantes acumulações sedimentares (Villwock, 1972) cuja origem e evolução depende principalmente do entendimento da resposta desses ambientes às variações do nível do mar.

Os primeiros artigos publicados sobre a origem dos ambientes deposicionais de barreiras costeiras foram descritos ainda no século XIX De Beaumont, 1885; Gilbert, 1885; McGee, 1890) e assumiram grande repercussão no século XX (Hoyt, 1967). Porém, foi somente no final da década de 1960 que o debate foi para primeiro plano do discurso científico, quando foi publicada uma série de artigos sobre a formação de barreiras relacionando-os ao clássico artigo de Hoyt (1967). Nestes trabalhos as barreiras costeiras foram classificadas como transgressivas e regressivas. As transgressivas se formam em associação com a erosão da linha de costa e da face litorânea (shoreface) (Fisher, 1968; Hoyt, 1967; Otvos, 1970), enquanto as regressivas relacionam-se à formação de cordões arenosos (transgressive dune ridges, foredune ridges $e$ beach-ridges) derivados do retrabalhamento pela ação de ondas ou da deposição de sedimentos eólicos.

A formação e evolução dos diversos sistemas de barreiras costeiras modernas ocorreu devido à elevação pós-glacial do nível do mar no Holoceno (ou Transgressão Marinha Pós-glacial - TMP) combinada à atuação de diversos processos costeiros (Sanders \& Kumar, 1975; Swift, 1976; Streif, 1989; Roy et al., 1994). A variação do nível do mar e o fluxo sedimentar local são tidos como os fatores principais que definiram a evolução das planícies sedimentares em toda a costa brasileira, tais como manguezais, praias, lagoas e deltas. Esses ambientes, no entanto, não podem ser analisados isoladamente porque compõem um sistema integrado (Woodroffe, 2002; Angulo et al., 2006).

Na Ilha do Maranhão, no litoral da Região Nordeste do Brasil, os sistemas de barreiras costeiras são classificadas no presente estudo em dois morfotipos principais, segundo classificação geral proposta por Roy et al. (1994): (i) Barreiras de Praias Anexadas (do inglês, Mainland Beach Barrier) que se caracterizam por uma topografia antecedente composta por falésias da Formação Itapecuru com gradiente íngreme, onde há perda contínua de areia pela costa erodida e; (ii) Barreiras de Esporões Arenosos ligadas a Cabeços de Promontórios (do inglês, Headland Spit Barrier) que se caracterizam por um sistema laguna-barreira-esporão ancorado longitudinalmente em falésias da Formação Itapecuru. Este último morfotipo desenvolve-se onde existe brusca variação de orientação da linha de costa ou onde a topografia antecedente é mais resistente à erosão marinha. Além disso, este morfotipo origina-se de um amplo transporte de sedimentos via deriva litorânea, cujo prolongamento é geralmente interrompido pelo efeito conhecido como espigão hidráulico, junto a elevados prismas de maré nas desembocaduras fluviais.

A Praia da Ponta da Areia desenvolve-se sobre um esporão arenoso de 2,5 km de extensão, iniciando-se nas falésias da Ponta do Farol e avançando até a desembocadura do Estuário do Anil (Figura 1). Nesta localidade onde se ancora o esporão arenoso, a sequência Itapecuru Superior aflora nas falésias adjacentes à praia e na região do intermar (Branner, 1902; Campbell, 1949; Bigarella \& Andrade, 1964). Esta praia oceânica encontra-se exposta a um regime de macromaré (amplitude de 3,5 m) de período semidiurno, com ondas oceânicas superficiais de gravidade de 1,5 m provenientes de $\mathrm{NE}$, que delineiam características de uma praia ultra-dissipativa na maré baixa e dissipativa sem bancos em condições de maré alta (Albuquerque, 2018).

Fundamentalmente, duas intervenções antropicas alteraram o equilíbrio sedimentar da Praia da Ponta da Areia: (i) a implantação da Barragem do Bacanga; (ii) o aprisionamento do Igarapé da Jansen. Ambas intervenções ocasionaram a drástica redução do prisma de maré do Estuário do Anil, com consequente desaparecimento do espigão hidráulico natural, além da formação de um amplo delta de maré vazante na foz do estuário (Banco da Minerva) e redução da largura 
da Praia da Ponta da Areia. Com a finalidade de conter o processo de erosão costeira na Praia da Ponta da Areia, foi construído um espigão transversal à linha de costa no extremo do esporão arenoso, totalizando $560 \mathrm{~m}$ de enrocamentos, visando a ampliação da praia e aprofundamento da foz estuarina pelo déficit de sedimentos a jusante.
O objetivo deste estudo é obter um melhor conhecimento acerca dos sistemas de barreiras costeiras do litoral da Ilha do Maranhão, estabelecendo um modelo evolutivo para a Praia da Ponta da Areia, via reconhecimento estratigráfico de suas alterações antrópicas e naturais.

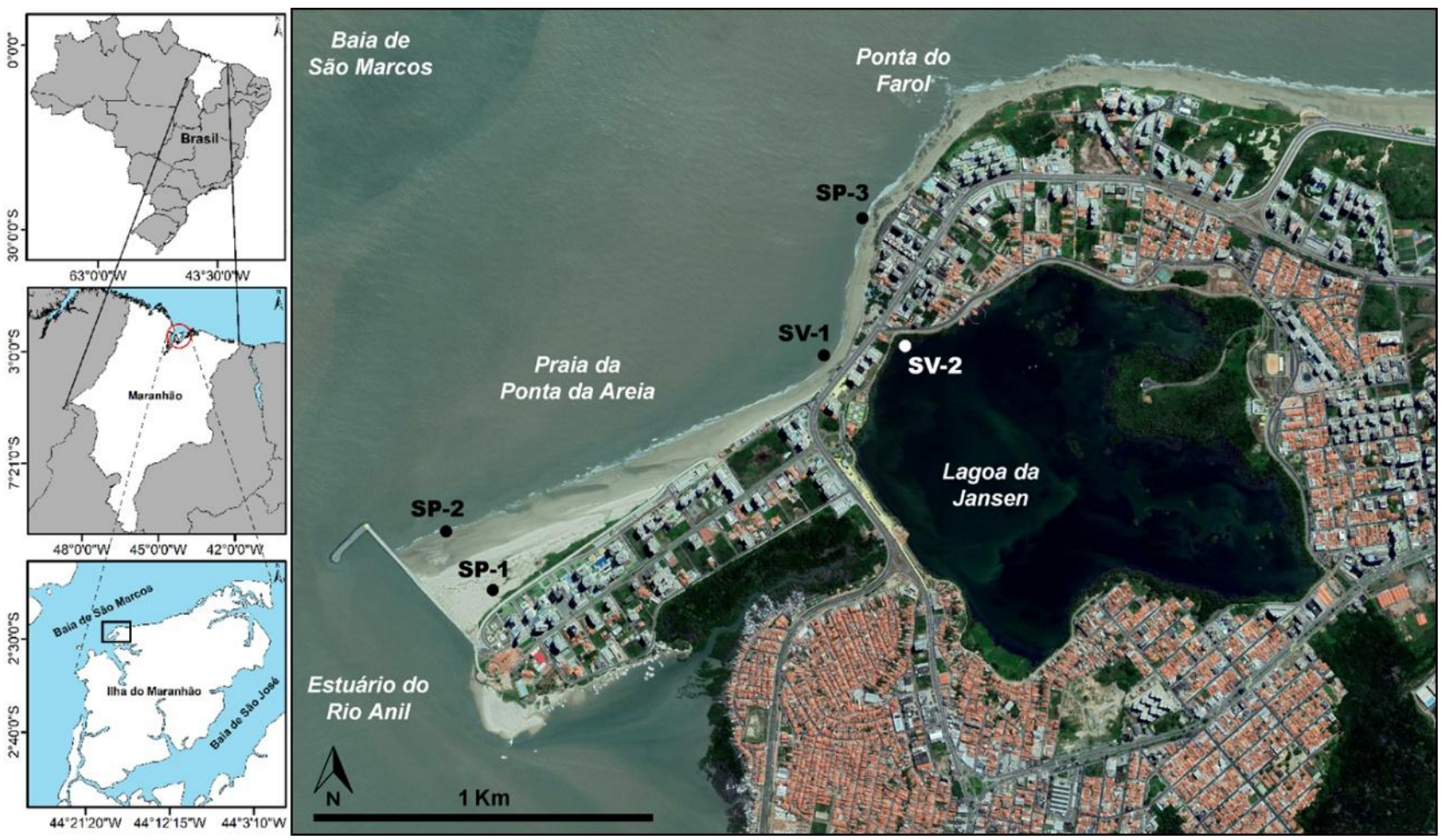

Figura 1 - Mapa de localização das sondagens realizadas na Praia da Ponta da Areia, São Luís, Maranhão, Brasil.

\section{MATERIAL E MÉTODOS}

O presente estudo utiliza-se de sondagens do tipo percussão e vibrocore para amostragens em sub-superfície. A primeira é utilizada para terrenos arenosos compactos, já a segunda é utilizada para terrenos lamosos pouco compactados. As sondagens a percussão foram realizadas com canos de PVC de 7,5 mm introduzidos por uma sequência de golpes, com um peso batente de 20 $\mathrm{kg}$, sobre uma braçadeira móvel fixada ao cano. As sondagens vibrocore, por sua vez, foram realizadas pela penetração de um cano de alumínio de $7,5 \mathrm{~cm}$ de diâmetro e $6 \mathrm{~m}$ de comprimento mediante a vibração de baixa frequência produzida pelo acionamento de um mangote vibrador (amplitude de vibração 0,85 mm a 12.500 RPM) acoplado ao cano.

Foram executadas cinco sondagens sendo três a percussão e duas a vibrocore. Duas sondagens a percussão (SP-1 e SP-2) foram realizadas transversais à linha de costa, no setor progradacional da praia à montante do espigão costeiro. A terceira sondagem a percussão (SP-3) foi realizada num setor com características de praia anexada na base do esporão arenoso. Já as sondagens a vibrocore foram realizadas no setor retrogradacional da praia, uma na face litorânea da barreira costeira e outra na margem do sistema lagunar (Lagoa da Jansen). As cotas altimétricas das sondagens foram aferidas mediante utilização de uma estação total e referenciadas a um $\mathrm{RN}$ do IBGE.

Em laboratório, os testemunhos foram abertos e descritos quanto aos parâmetros de cor (Munsell, 2009), compactação, textura, estruturas e fácies sedimentares. Após a descrição, separou-se alíquotas de $50 \mathrm{~g}$, a cada $10 \mathrm{~cm}$, partindo da base até o topo dos testemunhos, para serem realizadas análises granulométricas, de carbonato de cálcio e de matéria orgânica. As análises granulométricas seguiram a metodologia descrita em Suguio (1973). A proporção e o diâmetro dos grãos de areia foram determinados pelo método da peneiragem, utilizando a escala desenvolvida por Krumbein (1934) e a proporção de silte e argila foram 
determinados por técnicas de pipetagem baseada na lei de Stokes (1851) e classificados segundo tratamento estatístico de Folk \& Ward (1957).

Análises de ${ }^{14} \mathrm{C}$ segundo o método Accelerator Mass Spectrometry (AMS), em sedimentos orgânicos foram realizadas no Beta Analytics
Radiocarborn Dating Laboratory em Miami, Flórida, EUA. Para a calibração das amostras utilizou-se da base de dados MARINE04 (Hughen et al., 2004) e INTCAL04 (Reimer et al., 2004) interpolados segundo o ajuste ponderado de spline cúbico descrito em Talma \& Vogel (1993).

\section{RESULTADOS}

A sondagem SP-1 foi realizada sobre o sistema eólico na base do espigão da Ponta da Areia (Figura 1), obtendo um registro sedimentar de 4,20 m. Esta sondagem interceptou duas fácies sedimentares (Figuras 2 e 3). A fácies ER (esporão retrogradacional) tem espessura de 92 $\mathrm{cm}$, apresentando uma composição de areia fina com minerais pesados e cor bege (10YR 6/2) de moderadamente a bem selecionado. A base desta fácies indica um sistema praial retrogradacional, refletindo os processos erosivos praiais que antecederam a construção do espigão costeiro. A evidência desta natureza erosiva é caracterizada pela ocorrência de fragmentos de rochas ígneas e resíduos de construção civil na fácies ER indicando a presença de estruturas de contenção à erosão numa fase anterior ao espigão costeiro. $\mathrm{Na}$ fácies ER ocorrem conchas das famílias Arcidae, Columbellidae, Fasciolariidae, Vitrinellidae, Skeneidae, Escarphopia, Olividae, Veneridae, Litorinidae, Terebridae, Gaimmariidae, Rissoidae, Ostreidae, Epiitoniidae, sub-Família Ermarginulinae além do gênero Neoteredo sp. Próximo ao limite superior da fácies ER ocorrem três laminações com grande concentração de material bioclástico, no entanto, sua maioria não foi passível de identificação devido ao material encontrar-se amplamente fragmentado e bioturbado.
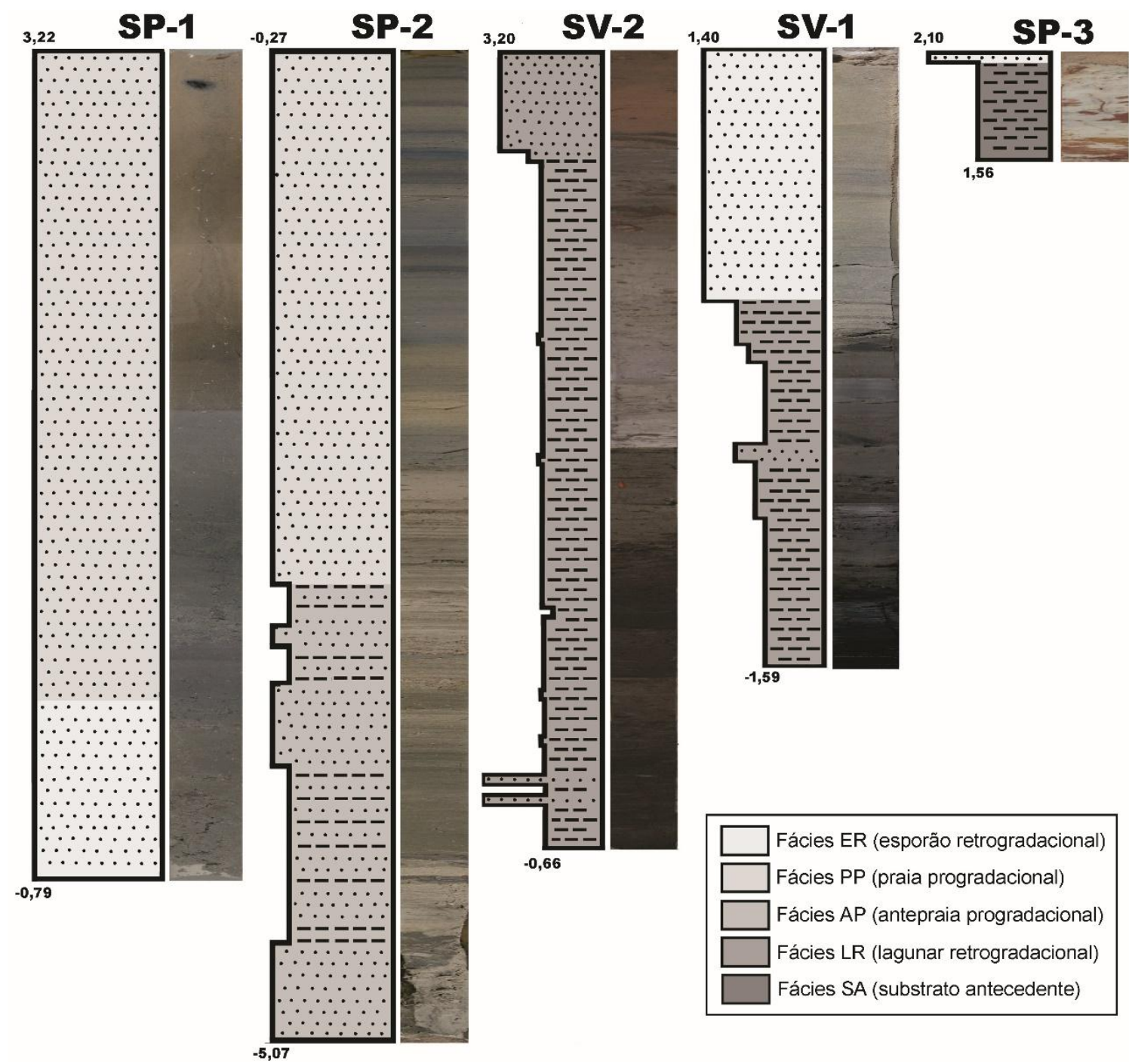

Figura 2 - Sondagens a percussão (SP) e vibrocore (SV) e suas respectivas fácies sedimentares identificadas, com as profundidades em metros referenciadas ao RN-IBGE. 


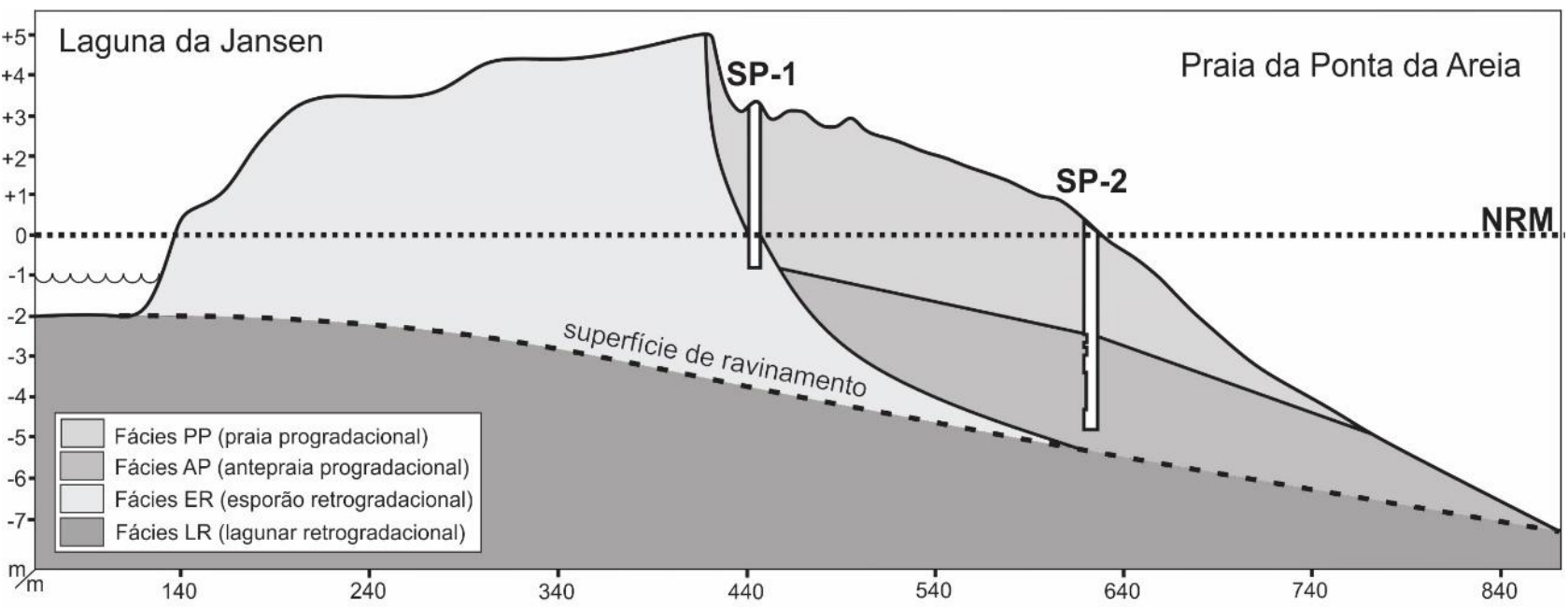

Figura 3 - Seção estratigráfica composta a partir das sondagens a percussão SP-1 e SP-2 e observações de campo. Observe figura 1 para localização no mapa.

De maneira discordante, a fácies ER sobrepõe-se a fácies PP (praia progradacional) indicando a presença de uma superfície erosiva (Figuras 2 e 3). Esta fácies tem 2,90 m de espessura, onde se verifica a deposição do sistema praial progradacional, com sedimentos bem compactados, variando de areia fina a areia muito fina $(2,3 \varphi$ a $3,1 \varphi)$ e de bem selecionado a pobremente selecionado com a predominância da cor bege (10YR 6/2). Na fácies PP ocorrem laminações de conchas e minerais pesados, fragmentos vegetais, marcas de raízes e sedimentos lateríticos. Na maior parte da fácies PP não foi possível realizar a taxonomia do material bioclástico principalmente pelo alto grau de fragmentação das conchas, restando somente a definição das famílias Arcidae, Gaimmariidae e Crassostrea.

A sondagem SP-2 foi realizada na continuidade da sondagem SP-1 (Figura 1), também sobre o sistema praial progradacional. Esta sondagem obteve um registro sedimentar de 4,90 m, interceptando duas fácies sedimentares (Figura 2). A fácies AP (antepraia progradacional) na base do registro apresenta 2,2 $\mathrm{m}$ de espessura com areia fina a muito fina $(2,62 \varphi$ a 3,72 $\varphi)$ pobremente selecionada a bem selecionada e muito compacta. Esta fácies contém lentes de argilas de 1 a 2 mm de espessura que são características de locais com baixa energia de onda ou mesmo locais abaixo da profundidade de fechamento (sensu Hallermeier, 1981). Estas lentes indicam o término da zona de intermaré inferior ou mesmo o início da zona de inframaré. Nesta fácies ocorrem pontualmente lentes de conchas fragmentadas, juntamente com rochas lateríticas de até $0,5 \mathrm{~cm}$ de diâmetro.
De maneira gradacional insere-se a fácies $\mathrm{PP}$, com 2,60 m, com laminações plano/paralelas de areia fina $(2,1 \varphi$ a $3,1 \varphi)$ moderadamente a bem selecionada, coloração acinzentada amarelada (10YR $2 \backslash 2$ até 5Y 5/2) e muito compacta. Disperso nesse intervalo, foram encontradas grandes quantidades de materiais bioclásticos (fragmentos de conchas) não identificáveis, fragmentos vegetais e rochas lateríticas que indicam um ambiente de alta energia exposto à ação de ondas, além de fragmentos vegetais e grãos oxidados. Os horizontes superiores da fácies PP apresentam laminações e pontos de oxidação que conferem uma coloração amarelada no topo da fácies.

Próximo ao ponto de ancoramento do esporão arenoso no início da Praia Ponta da Areia foi executada a sondagem SV-1, realizada segundo a técnica vibrocore, obtendo um registro sedimentar de $3 \mathrm{~m}$ (Figura 1). A sequência estratigráfica da sondagem $\mathrm{SV}-1$ se divide em duas fácies sedimentares (Figura 2). A fácies LR (lagunar retrogradacional) com espessura de 1,7 $\mathrm{m}$ indicativa de ambientes lagunares, apresentase com textura silte fino a silte grosso, de cor cinza escuro (coloração N1 a N5), pobremente a moderadamente selecionada e pouco compacta. Nesta fácies é possível encontrar fragmentos vegetais acomodados em laminações planoparalelas e marcas de raízes de até $1,5 \mathrm{~cm}$ de espessura, além de grandes quantidades de matéria orgânica dispersa que em alguns pontos alcança até $11 \%$ do peso total de sedimento. A base da fácies apresenta silte fino com fragmentos vegetais e fragmentos de conchas não identificáveis. Na fácies LR, especificamente na profundidade de $-1,55 \mathrm{~m}$ em relação ao NRM, 
uma amostra da parcela orgânica sedimentar (sedimento orgânico) foi separada e submetida à datação de ${ }^{14} \mathrm{C}$ obtendo-se a idade de $7.240 \pm 30$ anos AP. Na porção intermediária da fácies LR ocorrem fragmentos vegetais horizontalizados (acomodação plano-paralela) de até $1 \mathrm{~cm}$, fragmentos de cirripédios, e laminações de $2 \mathrm{~mm}$ plano-paralelas de areia, e valvas desarticuladas de Ostrea sp. Junto ao topo da fácies existe uma granodecrescência ascendente passando de silte fino a silte grosso onde ocorrem novamente laminações plano-paralelas de areia.

A fácies ER (esporão retrogradacional) com 1,3 $\mathrm{m}$ de espessura apresenta textura de areia fina $(2,72 \varphi$ e 2,99 $\varphi)$, de moderadamente a bem selecionadas, com coloração acinzentada variando de tons mais claros (10YR 8/2) a tons mais escuros (10YR 2/2), muito compacta e ocorre de forma discordante a fácies LR. Esta discordância é essencialmente erosiva criada por uma superfície de ravinamento (SR) onde são identificados seixos lateríticos e valvas desarti-culadas de Ostrea sp. Neste nível ainda existem marcas de oxidação de forma laminar e plano-paralela em meio a grande concentração de minerais pesados. Eventualmente esta superfície (SR) pode ser observada no estirâncio durante marés baixas de sizígia nos equinócios de março e setembro.

Na margem da Lagoa da Jansen na posição justaposta ao esporão foi realizada a sondagem SV-2 a vibrocore (Figura 1), estando seu topo na cota de 3,2 m em relação ao NRM, e amostrou um registro sedimentar de 3,86 cm (Figura 2).
Este testemunho amostrou somente a fácies LR havendo apenas um incremento de textura areia muito fina no topo, pobremente selecionada e muito compacta, de coloração predominantemente cinza escura (5GY 4/1 e 5YR 4/1). Na continuidade da fácies observa-se textura silte fino a silte grosso, de muito pobremente a moderadamente selecionada e pouco compacta, com uma coloração predominantemente cinza escuro (5G 4/1, N5 e N4). Ao longo de toda a extensão da fácies são encontrados fragmentos de raízes e laminações de matéria orgânica, assim como material orgânico disperso. Intercalações alternadas de lentes de areia, lentes de lama e de matéria orgânica, bioturbações foram frequentes assim como raízes com aspecto de oxidação. Da base desta fácies até a cota de 2,2 m ocorrem lentes de areia bioturbadas e preenchidas com matéria orgânica.

No outro extremo da Praia da Ponta da Areia, na fronteira com a Praia da Ponta do Farol (Figura 1), foi executada a sondagem SP-3 medindo apenas $54 \mathrm{~cm}$, estando a cota de 2,10 m em relação ao NRM (Figura 2). Foram identificadas duas fácies sedimentares neste testemunho: a fácies ER junto ao topo, de $6 \mathrm{~cm}$ de espessura e composição areia fina de coloração bege clara, moderadamente selecionada e cor 10YR 7/4; e a fácies SA (substrato antecedente) junto à base, classificada como silte médio, pobremente selecionado, com coloração variegada (10Y 8/2, 5Y 8/1, 10R 4/6 e 10YR 5/4) e sem estruturas sedimentares.

\section{DISCUSSÃO}

O presente estudo faz uso da estratigrafia para contextualizar os aspectos de longo e curto termo que regem a evolução do sistema de barreiras costeiras na Ilha do Maranhão. Este estudo envolveu 5 sondagens geológicas e uma datação radiocarbônica. Os dados foram integrados em três seções estratigráficas: uma representando a evolução costeira de longo termo representando os estágios naturais de desenvolvimento de uma barreira de esporão arenoso da Ponta da Areia; a segunda indicando como o esporão arenoso encontra-se ancorado na geologia antecedente; e a terceira indicando de que forma as alterações antrópicas podem modificar em curto termo a natureza destas barreiras costeiras.

As sondagens SP-1 e SP-2 encontram-se na extremidade do esporão arenoso da Ponta da Areia (Figura 1 e 3), setor este dominado pela dinâmica do canal do Rio Anil e o delta de maré vazante do Rio Anil também conhecido como Banco da Minerva. A praia deste setor exibe campo de dunas parabólicas, dunas frontais, embrionárias e uma face praial com presença de grandes calhas de maré. Este compartimento costeiro corresponde ao setor que progradou efetivamente com a instalação de um espigão costeiro. Este setor evoluiu rapidamente sobrepondo as fácies eólicas sobre as fácies praiais e fácies praiais sobre as fácies antepraiais, num contexto essencialmente progradacional. As sondagens SP-1 e SP-2 realizadas neste setor compõem, juntamente com a topografia do terreno, o transecto estratigráfico apresentado na figura 2, resultando em uma visualização bidimensional das fácies sedimentares nas imediações do espigão costeiro. 
A sondagem SP-1, comporta o início da fase progradacional da barreira costeira neste setor litorâneo. Seu desenvolvimento se dá imediatamente após a construção do espigão costeiro, quando as fácies de foreshore (fácies PP e fácies AP) iniciaram sua sobreposição a uma SR. Esta superfície representa os estágios ainda erosivos desencadeados pela ação de ondas que erodiam a barreira costeira numa fase anterior à construção do espigão costeiro. A definição desta transição do regime deposicional-retrogradacional para progradacional teve como principal evidência a presença de fragmentos de rochas ígneas e resíduos de entulho de construção civil neste horizonte. Estes materiais foram inseridos artificialmente no pós-praia como medida para conter o avanço das grandes marés de sizígia que anteriormente causavam destruição da orla. O material exótico presente nesta superfície limítrofe é indicativo de uma defasagem ou lag transgressivo (sensu Snedden \& Dalrymple, 1999) formado pelo retrabalhamento dos enrocamentos de contenção (seawalls), sob ação de ondas. Neste nível também foi comum a concentração de minerais pesados que tornam sua coloração (5Y 4/1) enegrecida quando comparada aos níveis superiores e inferiores. A concentração destes minerais é indicativa de uma elevada energia de ondas, resultando no retrabalhamento das fácies ER, assim como, dos frequentes processos erosivos que ocorriam na Praia da Ponta da Areia anteriormente à construção do espigão costeiro.

A fácies ER corresponde a depósitos de leques de sobrelavagem e/ou deltas de maré enchente que representam os principais ambientes deposicionais atuantes na fase de retrogradação do esporão da Ponta da Areia. No entanto o efeito espigão hidráulico desempenhado pelo canal de ligação Rio Anil e Rio Bacanga deve ter mantido aproximadamente constantes as dimensões do esporão da Ponta da Areia, principalmente pelo controle hidráulico da topografia antecedente desempenhada pelos remanescentes dos vales incisos destes canais. Desta forma, o prolongamento longitudinal deste esporão, deve ter sido construído em sua totalidade, imediatamente após ter sido estabelecido os níveis atuais do NRM (por volta de 7.000 anos AP). Esta idade corresponde a primeira aproximação do NRM da sua posição atual (Angulo et al., 1999). A taxonomia do material conquiliológico presente na fácies ER reflete um ambiente tipicamente estuarino. Nenhuma concha encontrada se apresenta em posição de vida, ou seja, indicam apenas uma concentração sedimentológica de bioclastos.

Na sondagem SP-1 o pacote sedimentar superior à SR é atribuído exclusivamente à fase de deposição sedimentar pós-espigão por ambientes deposicionais de pós-praia, estirâncio e eólico. As fácies sedimentares identificadas resultam da progradação destes ambientes deposicionais em direção ao centro da bacia. Estas fácies acumulam-se neste segmento costeiro principalmente pelo transporte de sedimentos via deriva litorânea de sentido WSW onde são retidos pelo espigão costeiro. Assim, a construção do espigão alterou o regime deposicional retrogradacional para progradacional, e esta transição ficou registrada por uma superfície erosiva marcando a interface das fácies superior (fácies PP e fácies AP) e inferior (fácies ER).

No topo da sondagem SP-1, encontram-se depósitos eólicos de dunas frontais e campos de dunas parabólicas. Estas dunas progradaram na medida em que a linha de costa foi sendo ampliada à montante do espigão, e até o momento estes ambientes deposicionais já progradaram cerca de $125 \mathrm{~m}$. Esta ampliação do sistema eólico ocorreu com preenchimento do espaço de acomodação criado pelo espigão costeiro, no entanto, no ano de 2015 o espaço de acomodação disponível na base e porção intermediária do espigão foi preenchido e os sedimentos começaram a cruzar (by-passing) o espigão. Este mecanismo de by-passing está sendo ampliado à medida que ocorre a ampliação do campo de dunas em decorrência da progradação da praia. Isto amplia a pista de vento (fetch) potencializando o transporte eólico, que neste caso ocorre transversalmente ao espigão devido ao sentido preferencial do vento neste setor. Como a estrutura do espigão foi urbanizada para fins turísticos esta transposição eólica ocasiona transtornos à população que frequenta o espigão.

A sondagem SP-2 foi executada próxima à extremidade do espigão da Ponta da Areia, mais precisamente sobre o início do sistema praial progradacional, há $292 \mathrm{~m}$ do início da antiga posição da linha de costa pré-espigão. Esta sondagem teve o intuito de ampliar o registro estratigráfico somando-se a sondagem SP-1 de forma a compor um registro mais completo das fácies progradacionais. Esta composição resultou na seção estratigráfica da figura 3. Nela puderam 
ser adquiridos os limites continentais da antepraia superior e os limites oceânicos (mar a dentro) do foreshore além de sua transição para antepraia inferior. Este contato foi definido pelas lentes de argilas da antepraia inferior, indicando os limites abaixo da profundidade de fechamento neste transecto.

No topo do testemunho SP-2 foi definida a fácies PP com laminações plano/paralelas de areia fina, muito compacta, com grandes quantidades de materiais bioclastos e rochas lateríticas que indicam um ambiente de alta energia exposto à ação de ondas. Além dos materiais indicativos de ambientes de alta energia foram encontrados fragmentos vegetais e pontos de oxidação, os quais são concentrados na zona de deposição de lixo da praia. As informações extraídas do registro sedimentar SP-1 e SP-2, demonstram as alterações no ambiente praial após a construção de um espigão costeiro, manifestadas pelo avanço da linha de costa em direção à Baía de São Marcos, em um local que antes sofria com a erosão e retração costeira. As fácies praiais se correlacionam às posições subaéreas do esporão arenoso (supra e entre-maré), enquanto a fácies da antepraia inferior correspondem às posições subaquosas (infra-maré). Abaixo dessas fácies encontram-se as argilas lagunares transgressivas sobre as quais o esporão arenoso migrou em direção do continente conforme correlação ao testemunho SV-1 e SV-2.

Junto ao setor mais erosivo da Praia da Ponta da Areia encontra-se o perfil estratigráfico indicado na figura 4. Este setor apresenta a menor faixa de areia de toda a praia, principalmente por encontrar-se à jusante de um enrocamento natural de rochas lateríticas na Ponta do Farol, que funciona como uma barreira que impede/ desvia o transporte longitudinal de sedimentos que alimentaria este setor costeiro (Figura 5).

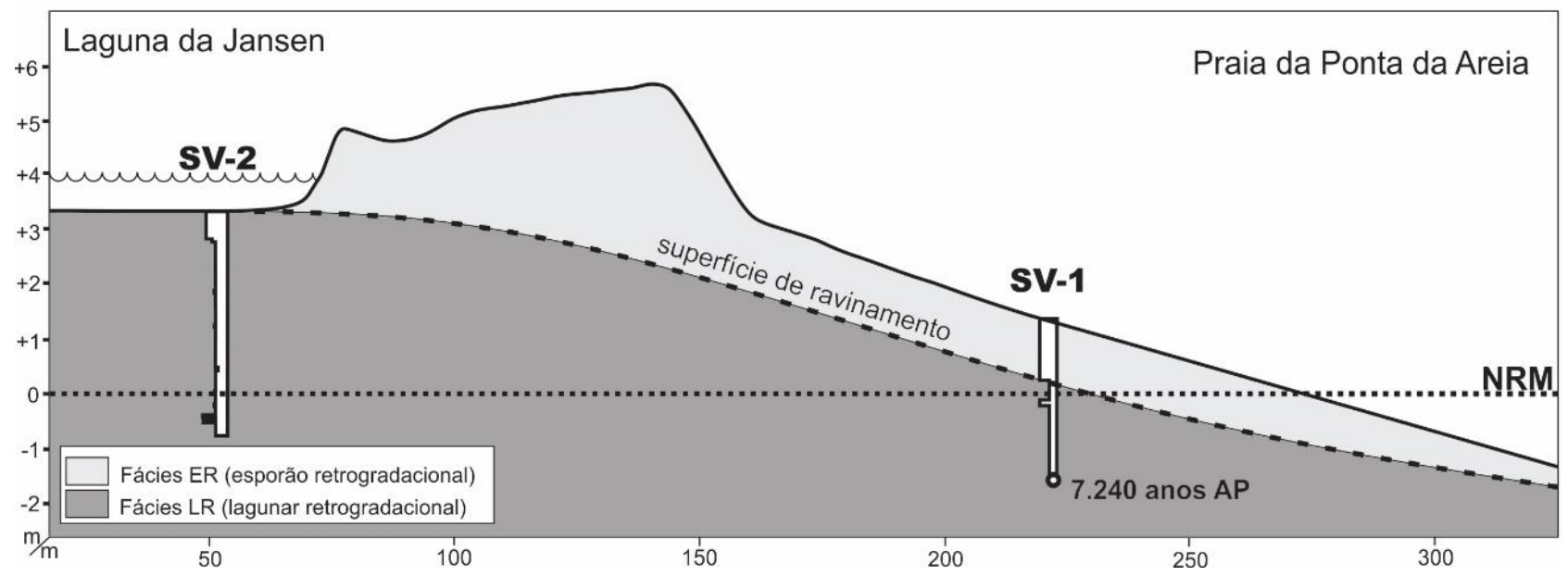

Figura 4 - Seção estratigráfica composta a partir das sondagens a vibrocore SV-1 e SV-2. Observe figura 1 para localização no mapa.

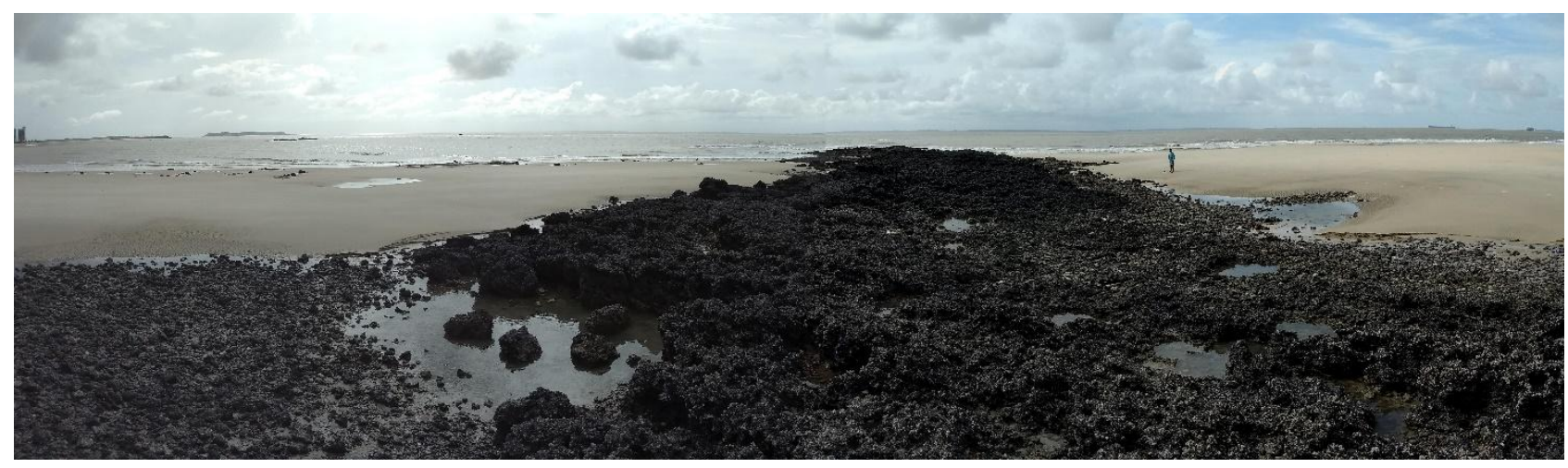

Figura 5 - Afloramento de rochas lateríticas na Praia da Ponta do Farol.

Este espigão natural foi formado pela erosão costeira atuante nas falésias da Ponta do Farol. A maior resistência à erosão destas falésias condiciona uma projeção da linha de costa nesta localidade, induzindo a processos de refração dife- renciada de ondas o que remove os sedimentos da face praial. A erosão das falésias da Ponta do Farol é provavelmente um fenômeno de longo termo. Litoestratigraficamente, na Praia da Ponta da Areia encontram-se duas unidades principais: (i) 
Formação Itapecuru (Mesozoico-Cretáceo Superior) e (ii) Formação Açuí (Quaternário) (Rodrigues et. al., 1994; El-Robrini et. al., 2006). Estas falésias representam exposições da Formação Itapecuru e apresentam tanto o limite de base como o seu limite de topo marcado por discordâncias não deposicionais definidas por horizontes ferruginosos com presença marcante de rochas lateríticas. São estas rochas que erodidas das falésias concentram-se na zona de arrebentação e estirâncio formando uma feição natural de dezenas de metros que se aproxima da feição de um espigão costeiro (Figura 5).

Neste mesmo setor costeiro onde as falésias aproximam-se da praia foi realizada a sondagem SP-3 (Figura 1), indicando o limite onde as barreiras de esporões arenosos ligados a cabeços de promontórios (Headland Spit Barriers) encontram-se ancoradas aos substratos antecedentes formando as Barreiras de Praias Anexadas (Mailand Beach Barriers). Este último morfotipo de barreiras costeiras representa a maior parte da Ilha do Maranhão, tendo como principal aspecto diagnóstico, a presença massiva do substrato antecedente à última TMP aflorando diretamente na praia. O reduzido estoque sedimentar das barreiras costeiras faz com que quase todo este litoral se encontre em erosão.

Na Praia da Ponta da Areia o setor com maior potencial erosivo coincide com um sistema do tipo laguna-barreira-esporão, onde o sistema barreira é repre-entado pelo esporão arenoso emerso enquanto a laguna é representada pela Lagoa da Jansen e terrenos adjacentes. Este setor compõe a seção estratigráfica na figura 4 a partir da integração das sondagens SV-1 e SV-2. Segundo Roy et al. (1994), sistemas de laguna-barreira holocênicos podem ser classificados em quatro subtipos morfoestratigráficos: barreiras regressivas, estacionárias, transgressivas e de praias anexadas (Mainland Beach Barrier). No esporão arenoso da Praia da Ponta da Areia, o que se verifica é uma barreira holocênica transgressiva onde a base do esporão enquadra-se no morfotipo de barreira de praia anexada, indicado pela presença do substrato que antecedeu à TMP (Figura 6).

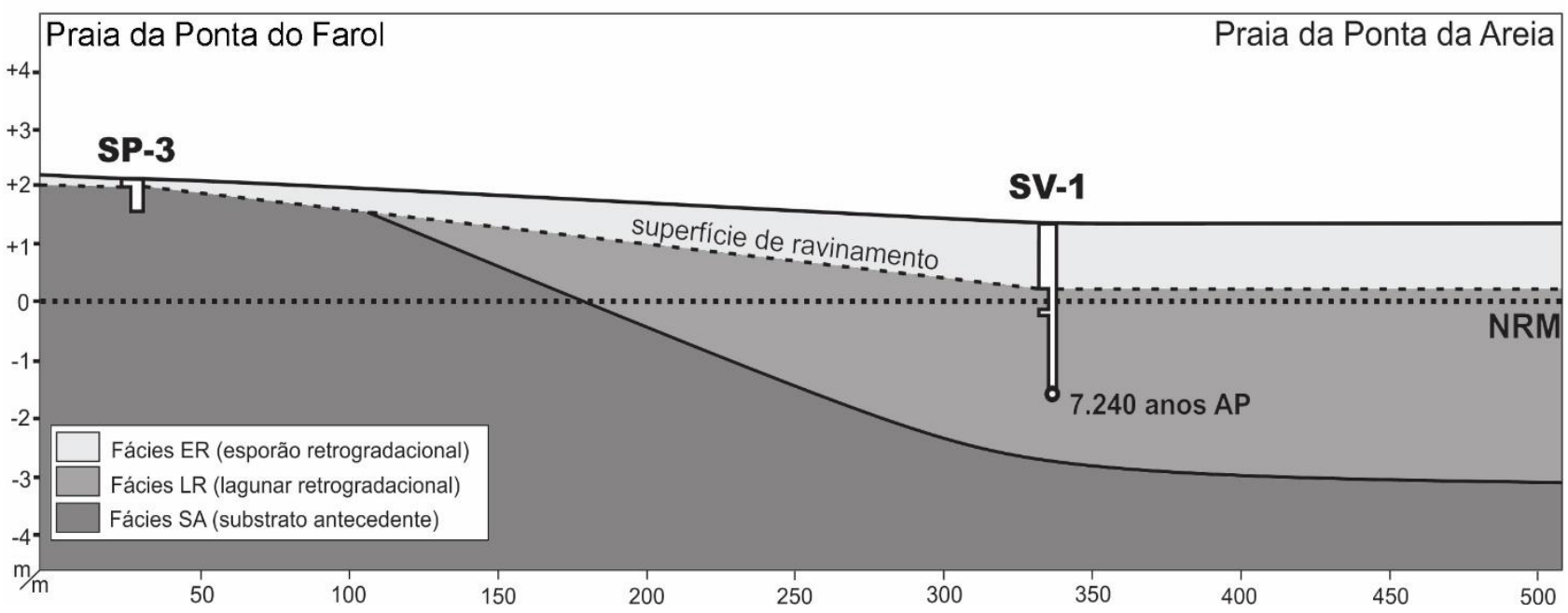

Figura 6 - Seção estratigráfica longitudinal à linha de costa composta a partir das sondagens a percussão SP-3 e a vibrocore SV-1. Observe figura 1 para localização no mapa.

A sondagem SV-1 evidencia os registros de uma fase transgressiva da barreira, na forma de depósitos arenosos do esporão sobrepostos a sedimentos tipicamente lagunares. A elevada concentração de fragmentos vegetais e raízes na fácies lagunar da sondagem SV-1 confirma que este ambiente deposicional formou-se em posições abrigadas por uma barreira costeira. A continuidade lateral da fácies lagunar estende-se até a sondagem SV-2 junto à Lagoa da Jansen. Este assoalho lagunar na sondagem $\mathrm{SV}-1$ tem seu topo posicionado na cota de 0,12 m do NRM, e neste ponto ocorre uma mudança abrupta para a fácies ER, onde bioturbações encontram-se preenchidas por areia, indicando tratar-se de uma superfície erosiva e neste caso coincidente com a SR. Sua base a $-1,59 \mathrm{~m}$ do NRM indicou a idade de $7.240 \pm 30$ anos AP. Esta posição bem como sua datação é compatível com as curvas de variação do NRM apresentadas para o litoral brasileiro (Suguio \& Martin, 1978, Angulo et al, 1999; Bezerra et al., 2003). Esta idade indica que por volta deste tempo já existia um sistema laguna-barreira nesta região, no entanto, este sistema estendia-se oceano adentro posicionando a barreira costeira além do que vemos hoje. Da mesma forma, a laguna que ocupava a retaguarda desta barreira (retrobarreira) era considerável- 
mente maior. As margens internas (em direção do continente) da Lagoa da Jansen fazem limite com a Formação Itapecuru, e eram assim também em tempos passados. Por volta de $7.240 \pm 30$ anos AP a barreira costeira instalada nesta posição estava ancorada nas falésias da Ponta do Farol, que também se apresentava oceano adentro em posições compatíveis com a barreira costeira. Assim, com o decorrer da TMP tanto a falésia da Ponta do Farol como o sistema laguna-barreiraesporão da Ponta da Areia evoluíram de forma a transgredir sobre os substratos mais antigos. Neste caso, com a barreira costeira avançando sobre o complexo lagunar e as falésias da Ponta do Farol regredindo frente à erosão provocada pela elevação do NRM. Na fácies LR da sondagem SV-1 entre 0,59 a 0,99 $\mathrm{m}$ do NRM ocorrem lentes de areia que representam os indicadores deste processo transgressivo. Estas lentes de areia enriquecidas com fragmentos de conchas e minerais pesados foram formadas pela coalescência de leques de sobrelavagem (washover) que invadiram o complexo lagunar em uma provável maré equinocial. Segundo Morton \& Sallenger (2003), este é o principal mecanismo de migração de barreiras trans- gressivas em direção ao continente.

A natureza estratigráfica descrita para a Praia da Ponta da Areia é comum em outros setores do litoral brasileiro com barreiras costeiras transgressivas (Dillenburg et al., 2006; Caldas et al., 2006 Lima et al., 2012 e Lima, 2012). A sondagem SV-2, executada sobre a atual Lagoa da Jansen, interceptou a continuidade da fácies lagunar (LR) encontradas na sondagem SV-1. Os registros sedimentares da sondagem SV-2 indicam condições hidrodinâmicas relativamente mais elevadas na base do registro quando ainda havia uma larga conexão do complexo lagunar com o oceano. este tempo a variação de maré atuante na retrobarreira permitia a exposição de seus sedimentos durante as marés baixas de sizígia o que se traduz nas areias oxidadas e com baixos teores de material orgânico na base do registro sedimentar. A sondagem SV-2 comporta a evolução estratigráfica desta retrobarreira desde quando está ainda era uma laguna, ou seja, ainda possuía uma comunicação efetiva com o oceano até o seu estágio atual, quando foi transformada numa lagoa costeira com controle manual de sua comunicação com o oceano através de uma comporta.

\section{CONCLUSÃO}

A natureza estratigráfica da barreira costeira na Praia da Ponta da Areia foi definida como uma sequência sedimentar retrogradacional caracterizada pela migração em direção ao continente de um esporão arenoso ligado a um promontório (Headland Spit Barrier). A construção de um espigão costeiro na Praia da Ponta da Areia alterou esta natureza estratigráfica, passando a comportar um sistema progradacional nas imediações do espigão, onde ambientes distais (antepraia) são sotopostos por ambientes proximais (foreshore).

Os registros estratigráficos desta transição (fase retrogradacional para a fase progradacional) da barreira costeira iniciam-se após a construção do espigão costeiro, ocasionando a sobreposição da SR por fácies da praia/antepraia progradacional. A fase retrogradacional acomoda os depósitos arenosos do esporão arenoso (Headland Spit Barrier) sobrepostos a sedimentos essencialmente lagunares. Esta fase envolveu tanto a origem (instalação) como a migração em direção do continente do esporão arenoso da Ponta da Areia. A datação radiométrica dos sedimentos lagunares obteve a idade de 7.240 \pm 30 anos AP indicando que neste tempo, a lagoa se estendia em direção a Baía de São Marcos e era protegida por uma barreira costeira, ancorada às falésias da Ponta do Farol.

O conjunto dos dados apresentados neste estudo permitiu elucidar as relações existentes entre o comportamento de uma barreira regressiva originada de uma intervenção antrópica (espigão costeiro) em contraponto com a evolução natural de um sistema transgressivo de esporão arenoso que por volta de $7.240 \pm 30$ anos AP que originou o sistema lagunar ocupado hoje pela Lagoa da Jansen.

O compartimento inicial da Praia da Ponta da Areia no limite com a Praia da Ponta do Farol pode ser caracterizado como uma barreira de praia anexada (Mainland Beaches Barrier) devido à exposição permanente dos sedimentos da Formação Itapecuru na linha de costa, restando um pequeno espaço de acomodação para os sedimentos quaternários. Observando-se a morfologia do conjunto praia/falésias da Ilha do Maranhão é possível afirmar que além de barreiras transgressivas, a maior parte das praias oceânicas desta ilha enquadra-se na classificação 
de barreiras de praias anexadas.

A natureza erosiva da Praia da Ponta da Areia encontra-se vinculada à morfologia transgressiva das barreiras costeiras instaladas nesta localidade, no entanto o setor erosivo mais pronunciado da Praia da Ponta da Areia encontrase localizado nas imediações da zona sombra de afloramentos lateríticos que desempenham funções semelhantes à de um espigão, ancorado as falésias da Ponta do Farol.

\title{
AGRADECIMENTOS
}

\author{
Os autores agradecem ao CNPq pelo apoio financeiro (Processo 448517/2014-0).
}

\section{REFERÊNCIAS}

ALBUQUERQUE, S.S. Estratigrafia, Morfodinâmica e Evolução de um Esporão Arenoso em Ambiente Macromaré: Ponta Da Areia, São Luís -MA. São Luís, 2018, 117 p. Dissertação (Mestrado em Oceanografia), Programa de Pós-Graduação em Oceanografia- Universidade Federal do Maranhão.

ANGULO, R.J.; GIANNINI, P.C.F.; SUGUIO, K.; PESSENDA, L.C.R. The Relative Sea-Level Changes In The Last 5,500 Years Sourthern Brazil (Laguna-Imbituba Region, Santa Catarina State) Based On Vermetid ${ }^{14} \mathrm{C}$ Ages. Marine Geology, Amsterdan, v. 159, n. 1-4, p. 327-339, 1999.

ANGULO, R.J.; LESSA, G.C.; SOUZA, M.C. A critical review of Mid- to Late Holocene sea level fluctuations on the eastern Brazilian coastline. Quaternary Science Review, v. 25, p. 486-506, 2006.

BELKNAP, D.F. \& KRAFT, J.C. Influence of antecedent geology on stratigraphic preservation potential and evolution of Delaware’s barrier systems. Marine Geology, v. 63 p. 235 262, 1985.

BEZERRA, F.H.R.; BARRETO A.M.F.; SUGUIO K. Holocene sea-level history on the Rio Grande do Norte state coast, Brazil. Marine Geology, v. 196, p. 73-89, 2003.

BIGARELLA, J.J. \& ANDRADE, G.O. Considerações sobre a estratigrafia dos sedimentos cenozoicos em Pernambuco (Grupo Barreiras). Arquivo Instituto de Ciências da Terra, Recife, n. 2, p. 2-14, 1964.

BRANNER, J.C. Geology along the Pernambuco coast south of Recife. Geol. Soc. Amer., v. 13, p. 58-92, 1902.

CALDAS, L.H.O.; STATTEGGER, K.; VITA, H. Holocene sealevel history and coastal evolution: evidences from coastal sediments of the northern Rio Grande do Norte coast, NE Brazil. Marine Geology, Amsterdam, v. 228, n. 1-4, p. 39-53. 2006.

CAMPBELL, D.F. Revised report on the reconnais-sance geology of the Maranhão Basin. Belém: Petrobras, Rept. v. 7 , 1949.

De BEAUMONT, L.E. Lecons de Geologie Practique. Septieme lecon. Bertrand, Paris, p. 221-252, 1845.

DILLENBURG, S.R.; TOMAZELLI, L.J.; HESP, P.A.; BARBOZA, E.G.; CLEROT, L.C.P.; SILVA, D.B. Stratigraphy and evolution of a prograded, transgressive dunefield barrier in southern Brazil. Journal of Coastal Research SI, v. 39 n. 1 p. 132-135, 2006.

El-ROBRINI, M.; SILVA, M.; SILVA Jr. P.; SILVA Jr. O.; FRANÇA, C. Erosão e progradação do litoral brasileiro. Ministério do Meio Ambiente (MMA), Brasília, DF, Brasil. In: Dieter Muehe (org.), 2006. Disp. on-line em: http://www.mma.gov.br/publicacoes/gestao-

territorial/category/80-gestao-costeira-g-erosao-e-progradacao

FISHER, J.J. Barrier island formation: discussion. Geological Society of American. Bulletin, v. 79 p. 421-426, 1968.

FOLK, R.L. \& WARD, W.C. Brazos River Bar: Study and significance of grain size parameters. Journal Sedimentary Petrology, v. 27, n. 1, p. 3-26. 1957.

GILBERT, G.K. The topographic features of lake shores. US Geological Survey, 5th Annual Report, p. 69-123, 1885.

GLAESER, J.D. Global distribution of barrier islands in terms of tectonic setting. Journal of Geology, v. 86, p. 283-297, 1978.
HALLERMEIER, R.J. A profile zonation for seasonal sand beaches from wave climate, Journal of Coastal Engineering, v. 4, p. 253-277, 1981.

HOYT, J.H. Barrier island. formation: Geol. Soc. America Bull., v. 78, p. 1125-1136, 1967.

HUGHEN, K.A.; BAILLIE, M.G.L.; BARD, E.; BECK, J.W.; BERTRAND, C.J.H.; BLACKWELL, P.G.; BUCK, C.E.; BURR, G.S.; CUTLER, K.B.; DAMON, P.E.; EDWARDS, R.L.; FAIRBANKS, R. G.; FRIEDRICH, M.; GUILDERSON, T.P.; KROMER, B.; MCCORMAC, G.; MANNING, S.; BRONK, R.C.; REIMER, P.J.; REIMER, RON, W.; REMMELE, S.; SOUTHON, J.R.; STUIVER, M.; TALAMO, S.; TAYLOR, F.W.; PLICHT, J. VAN DER; WEYHENMEYER, C.E. Marine 04 Marine Radiocarbon Age Calibration, 0-26 Cal kyr BP. Radiocarbon, v. 46, n. 3, p. 1059-1086, 2004.

KRAFT, J.C.; CHRZASTOWSKI, M.J.; BELKNAP, D.F.; TOSCANO, M.A.; FLETCHER, C.H. The transgressive barrier-lagoon coast of Delaware: Morphostratigraphy, sedimentary sequences and responses to relative rise in sea level, In: NUMMEDAL, D.; PILKEY, O.H.; HOWARD, J.D. (Eds.): The Society of Economic Paleontologists and Mineralogists, Special Publication, n. 41, p. 129-143, 1987.

KRUMBEIN, W.C. Size frequency distribution of sediments. Journal of Sedimentary Petrology, v. 4, p. 65-77, 1934.

LIMA, L.G. Estratigrafia e evolução holocênica de uma barreira costeira transgressiva/regressiva, litoral Norte do Rio Grande do Sul. Porto Alegre, 2012, 116 p. (Tese Doutorado). Instituto de Geociências, Univ. Fed. do Rio Grande do Sul

LIMA， L.G.; DILLENBURG, S.R.; MEDEANIC, S.; BARBOZA, E.G.; ROSA, M.L.C.C.; TOMAZELLI, L.J.; DEHNHARDT, B.A.; CARON, F. Sea-level rise and sediment budget controlling the evolution of a transgressive barrier in southern Brazil. Journal of South American Earth Sciences, v. 42, p. 27-38, 2013.

MCGEE, W.D. Encroachments of the sea. Forum v. 9, p. 437449, 1890.

MORTON, R.A. \& SALLENGER, A.H. Morphological impacts of Extreme Storms on Sandy Beaches and Barriers. West Palm Beach, Florida. Journal of Coastal Research v. 19, n. 3 p. 560 573, 2003.

OTVOS, E.G. Development and migration of barrier islands, northern Gulf of Mexico. Geol. Soc. Am. Bull., v. 81, p. 241246, 1970

REIMER, P.J.; BAILLIE, M.G.L.,; BARD, E.; BAYLISS, A., BECK, J.W.,; BERTRAND, C., BLACKWELL, P.G., BUCK, C.E., BURR, G.; CUTLER, K.B.; DAMON, P.E., EDWARDS, R.L.; FAIRBANKS, R.G., FRIEDRICH, M., GUILDERSON, T.P.; HUGHEN, K.A; KROMER, B.; MCCORMAC, F.G.,; MANNING, S.; BRONK R.C.; REIMER, R.W.,; REMMELE, S.; SOUTHON, J.R., STUIVER, M.; TALAMO, S.; TAYLOR, F.W., VAN DER PLICHT J., E.; WEYHENMEYER, C.E., Radiocarbon, v.46, p. 1029-1058, 2004.

RODRIGUES, T.L.N. Programa Levantamentos Geológicos Básicos do Brasil. São Luís. Folha SA.23-Z-A, Cururupu. Folha SA.23-X-C, Estado do Maranhão. Brasília, CPRM, 1994. ROY, P.S.; COWELL, P.J.; FERLAND, M.A.; THOM, B.G. 
Wave Dominated Coasts. In: CARTER R.W.G.;WOODROFFE CD (Eds.), Coastal Evolution, Late Quaternary Shoreline Morphodynamics, Cambridge: Cambridge University Press, p. 121-186, 1994.

SANDERS, J.E. \& KUMAR, N. Evidence of shoreface retreat and in-place "drowning", during Holocene submergence of barriers, shelf off Fire Island, New York. Geological Society of America Bulletin, v. 86 p. 65-76, 1975.

SNEDDEN, J.W. \& DALRYMPLE R.W. Modern shelf sand ridges; from historical perspective to a unified hydrodynamic and evolutionary model: Society for Sedimentary Geology, Special Publication, v. 64, p. 13-28, 1999.

STOKES, G.G. On the effect of the internal friction of fluids on the motion of pendulums: Cambridge Philosophical Society, Transactions, v. 9, n. 8, p. 287, 1851.

STREIF, H. Barrier islands, tidal fiats, and coastal marshes resulting from a relative rise of sea level in East Frisia on the German North Sea coast. Coastal Lowlands. Geology and Geotechnology, Kluwer, Dordrecht, p. 213-233, 1989.

SUGUIO, K. Introdução à Sedimentologia. Edgard Blücher ltda./EDUSP, São Paulo, SP, 317p., 1973.

SUGUIO, K. \& MARTIN, L. Formações quaternárias marinhas do litoral paulista e sul fluminense. Spec. Publ. Intern. Symp. Coastal Evolut. Quaterrnary, São Paulo, v. 1, p. 1-55. 1978.

SWIFT, D.J.P. Continental shelf sedimentation. In: STANLEY, D., SWIFT, D.J.P. (Eds.), Marine Sediment Transport and Environmental Management. John Wiley \& Sons, New York, p. $311-350,1976$.
TALMA, A.S. \& VOGEL, J.C. A Simplified Approach to the Calibration of Radiocarbon Dates. Radiocarbon v. 35 n. 2, p. 317-322, 1993.

VILLWOCK, J.A. Contribuição à Geologia do Holoceno da Província Costeira do Rio Grande do Sul. Porto Alegre, 113 p, 1972. Dissertação (Mestrado), Curso de Pós-Graduação em Geociências, Universidade Federal do Rio Grande do Sul.

WALKER, R.G. Facies, facies models and modern stratigraphic concepts, 1-14 In: WALKER, R.G. \& JAMES, N.P. (Eds.), Facies models: Geological Association of Canada, St.Johns, Newfoundland, 1992.

WALTHER, J. Einleitung in die Geologie als historische Wissenschaft. In: Lithogenesis der Gegenwart. Jena: G. Fischer, Bd. 3, p. 535-1055, 1894.

WOODROFFE, C. Coats form, process and evolution, Londres, Cambridge, p. 248-320, 2002.

Submetido em 20 de março de 2019 Aceito para publicação em 27 de outubro de 2020 